\title{
Underestimated pulmonary hemorrhage-a fatal complication combined with systemic air embolism after CT-guided lung biopsy: a case description
}

\author{
Xingyu Fang ${ }^{1}$, Jialin $\mathrm{Li}^{2}$, Bin Sun ${ }^{1}$, Mingxia Liu ${ }^{1}$, Zhiquan Tang ${ }^{1}$ \\ ${ }^{1}$ Department of Radiology, PLA 305 Hospital, Beijing, China; ${ }^{2}$ Department of Laboratory, PLA 305 Hospital, Beijing, China \\ Correspondence to: Zhiquan Tang, MD. Department of Radiology, PLA 305 Hospital, No. 13 Wenjin Street, Beijing 100017 , China. \\ Email: radiology305@126.com.
}

Submitted Nov 21, 2020. Accepted for publication Feb 04, 2021.

doi: 10.21037/qims-20-1290

View this article at: http://dx.doi.org/10.21037/qims-20-1290

\section{Introduction}

Computed tomography (CT)-guided percutaneous lung biopsy is a widely used interventional procedure to diagnose various lung lesions. The most common complications are pneumothorax and pulmonary hemorrhage, although most complications are mild, non-fatal, and do not require additional clinical treatment. However, air embolism is a rare and serious complication of CT-guided percutaneous lung biopsy, with an incidence rate of approximately 0.02 $0.4 \%$, in which the incidence rates of air embolism with clinical symptoms is $0.02-0.1 \%(1-5)$, and the prognosis is poor. This report describes the imaging manifestations and shares our experiences and lessons of a case involving multiple complications during CT-guided percutaneous lung biopsy.

\section{Case presentation}

A 64-year-old female patient was admitted to our hospital due to the accidental discovery of a solid pulmonary nodule in the superior segment of the lower lobe of the right lung during a regular health checkup (Figure 1). After 2 weeks of standard antibiotic treatment, there were no significant changes to the nodule. A percutaneous CTguided lung biopsy was subsequently performed. Before the procedure, routine blood, blood coagulation function, and electrocardiogram (ECG) were performed, and the patient's results were all in the normal range. A radiologist performed the procedure with 10 years of experience with a 64-row CT (General Electric Lightspeed, Milwaukee, USA) using an 18-gauge coaxial cutting needle (length $=15 \mathrm{~cm}$, PAJUNK, Geisingen, Germany), which is our most commonly utilized puncture needle.

The patient lay down in the prone position and was marked on the body surface. After scanning her body at a thickness of $5 \mathrm{~mm}$ layer and intervals of $5 \mathrm{~mm}$ layer, the needle entry point and route were determined. Based on SmartStep technology, which takes the puncture point as the central plane, nine layers were scanned at a thickness of $2.5 \mathrm{~mm}$ layer and intervals of $2.5 \mathrm{~mm}$ layer, and the biopsy needle gradually penetrated into the lungs. The distance to the nodule was $8 \mathrm{~cm}$ from the skin and $5.5 \mathrm{~cm}$ from the pleura. When the needle tip was close to the nodule (Figure 2), the needle was advanced approximately $1 \mathrm{~cm}$, and the patient was told to hold her breath, and then the needle was pulled out after stimulating the biopsy gun. After removing the puncture needle, the patient developed a severe cough and approximately $10 \mathrm{~mL}$ hemoptysis, and 2 units of thrombin were immediately administered (via injection).

Meanwhile, the patient became restless and unconscious. CT scanning showed a significant volume of air in the left atrium (Figure $3 A$ ) and a small volume in the spinal artery (Figure 3B), and the occurrence of systemic air embolism was confirmed. The patient was immediately placed in the supine position and was given $6 \mathrm{~L} / \mathrm{min}$ oxygen via a nasal catheter. Her vital signs at that time were as follows: blood pressure (BP) 110/70 mmHg, heart rate (HR) 110, respiratory rate (RR) 28 and pulse oxygen saturation 


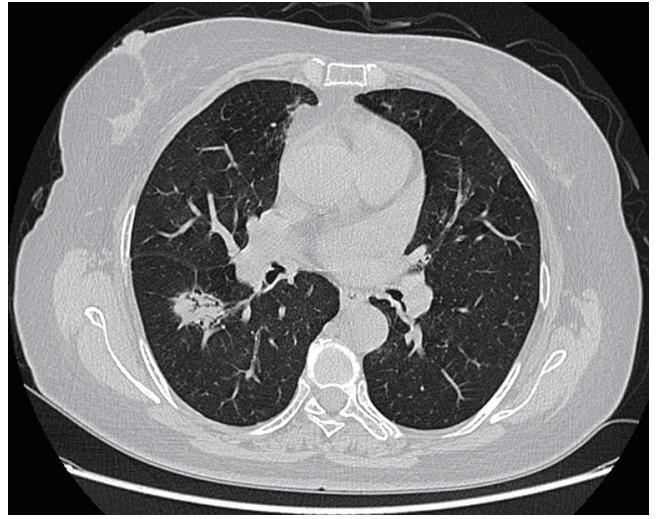

Figure 1 CT showed a solid nodule with burr, inflatable bronchus sign, and pleural traction sign in the lower lobe of the right lung. CT, computed tomography.

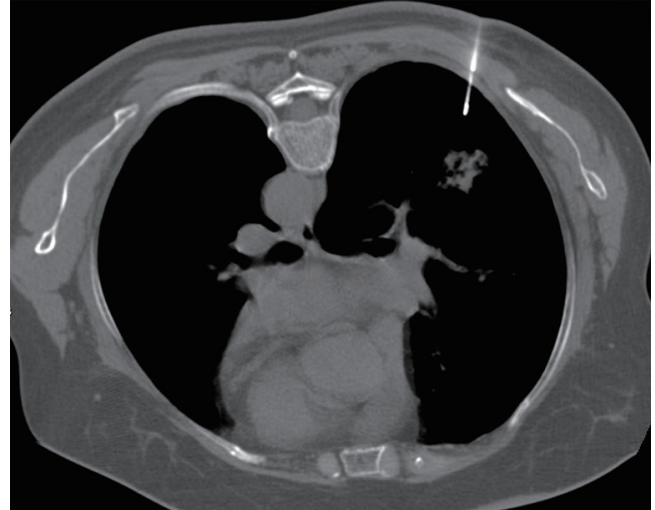

Figure 2 The biopsy needle tip was introduced near the nodule after penetrating the right lower lobe at a depth of $6 \mathrm{~cm}$ from the skin.
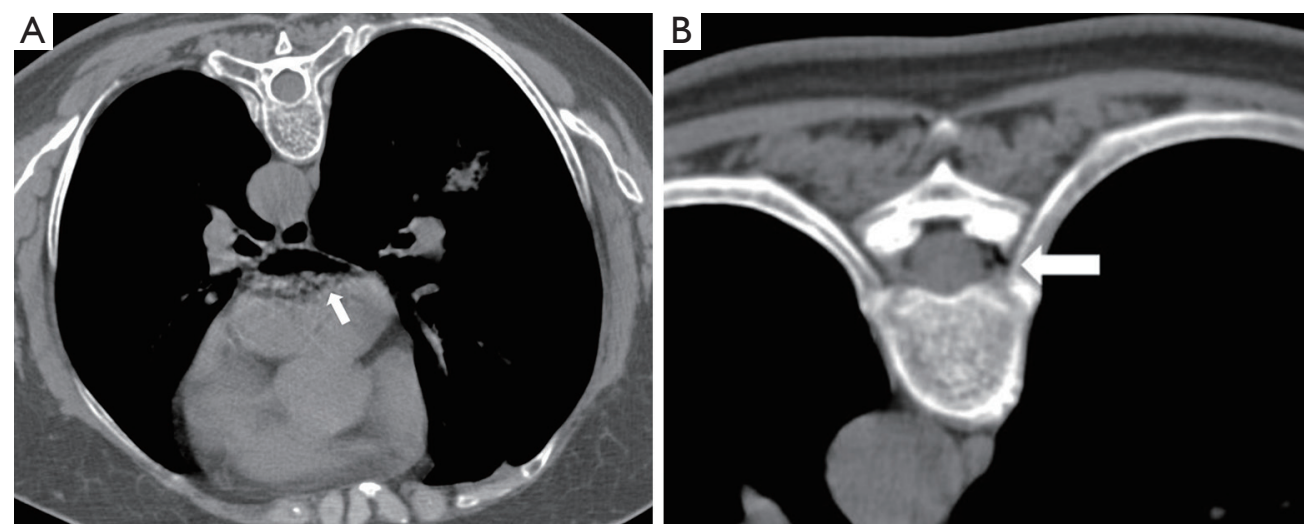

Figure 3 An immediate CT scan reveals the air after the patient became unconscious. (A) CT showed a significant volume of air (about $25 \mathrm{~mL}$ ) in the left atrium and (B) a small volume in the spinal artery (arrows). CT, computed tomography.

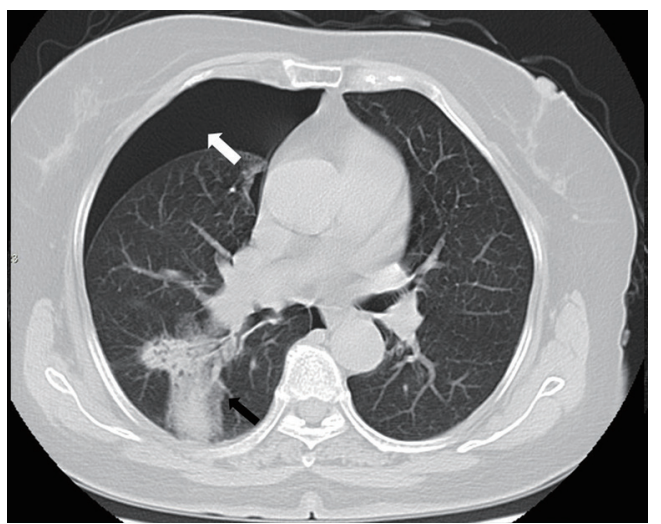

Figure 4 CT showed pulmonary hemorrhage around the puncture needle (black arrow) and a significant pneumothorax (white arrow) after the procedure. CT, computed tomography.
$\left(\mathrm{SpO}_{2}\right)$ 96\%. A subsequent head CT showed no significant abnormalities, and a chest CT showed pulmonary hemorrhage around the puncture needle as well as a significant pneumothorax, which was subsequently assessed at approximately 30-35\% (Figure 4).

After this, the patient was transferred to the Department of Neurology for further treatment. Nervous system examination showed that she was lethargic, had a weakened pharyngeal reflex, and a positive Babinski sign. Her tongue was extended to the right, her mouth angle was skewed to the left, her left upper limb's muscle strength was grade 0 , and her lower limbs' muscle strength was grade 1. No obvious abnormality was found in the ECG; however, the diffusion-weighted imaging (DWI) sequence of the head magnetic resonance imaging (MRI) only showed 

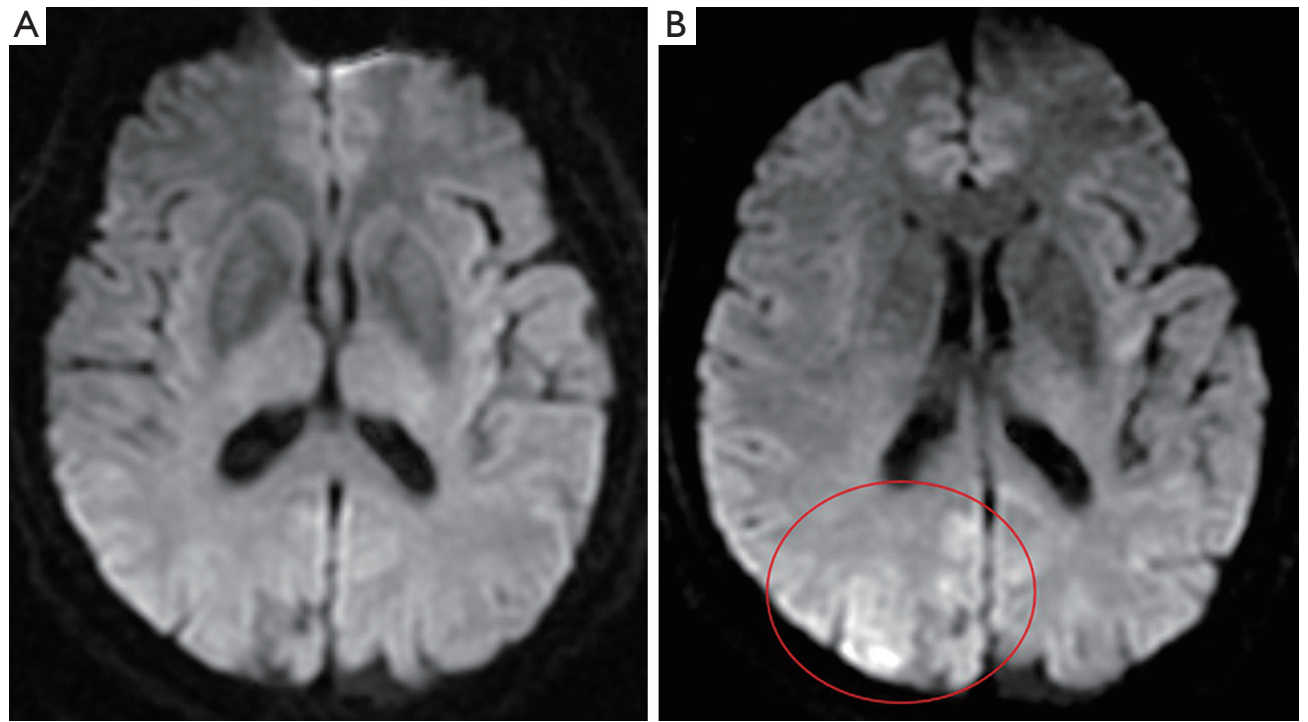

Figure 5 Head MRI performed before and after the lung biopsy. (A) The DWI sequence of the head MRI showed no obvious abnormality 2 days before the lung biopsy and (B) a high signal in the right parietal lobe cortex (red circle) 2 hours after the lung biopsy. DWI, diffusionweighted imaging.

a high signal in the right parietal lobe cortex (Figure 5), which could not fully explain the neurological symptoms and physical examination. This was likely because the MRI examination could not fully reflect the severity of the cerebral infarction, as the interval between the MRI and the puncture was only 2 hours.

In the neurology ward, the patient was given oxygen continuously $(6 \mathrm{~L} / \mathrm{min})$ via a nasal catheter which was the basic treatment for pneumothorax, and her $\mathrm{SpO}_{2}$ was stable at more than $95 \%$. The patient's family members rejected our suggestion of closed thoracic drainage for the treatment of the pneumothorax. Considering the pulmonary hemorrhage, we did not use thrombolytic, antiplatelet, or anticoagulant drugs to treat the cerebral infarction; only edaravone (protecting neuronal cells) and rehydrationnutritional treatment were given. Our hospital does not have hyperbaric oxygen therapy equipment. We had already contacted another hospital for hyperbaric oxygen therapy the next day and planned to perform another head MR scan before treatment if the patient's vital signs were stable. At approximately 00:00 that night, the patient suddenly experienced shortness of breath, shallow and fast breathing, and her $\mathrm{SpO}_{2}$ decreased to $60 \%$. Her other vital signs at that time were as follows: BP 130/85 $\mathrm{mmHg}$, HR 110 and RR 44. After sucking out about $30 \mathrm{~mL}$ of dark red blood through a sputum suction tube, the patient's $\mathrm{SpO}_{2}$ did not increase. The patient's family members refused to apply invasive rescue, and the patient died as a result. Table 1 shows the timeline of important events related to the changes of the patient's condition and corresponding management.

\section{Discussion}

Systemic air embolism is a rare complication during CTguided percutaneous lung biopsy, which we encountered for the first time (in almost 2,000 cases) since we launched this technology. Relevant systemic air embolism factors include the number of biopsies, needle depth, prone positions, coughing during operation, lesion located in the lower lobe, lesion located above the left atrium level vasculitis, and minor or cavity lesions (6-8). In our patient's case, the possible relevant factors included intraoperative cough, prone position, and lesion located above the left atrium level.

The mechanisms of air embolism caused by CT-guided percutaneous lung biopsy have not been fully elucidated. Possible mechanisms include the following: (I) the air directly enters the pulmonary vein through the puncture needle. Specifically, the air and pulmonary vein could be connected directly when the needle core is pulled out. If the patient has a deep inspiratory action at this time, a lower pulmonary venous pressure relative to atmospheric pressure could result, and thus, the air could enter the 
Table 1 Timeline of important events

\begin{tabular}{|c|c|}
\hline Time & Event \\
\hline 13:00 & Started the biopsy \\
\hline 13:26 & $\begin{array}{l}\text { Cough and hemoptysis after the needle was } \\
\text { removed; } 2 \text { units of thrombin injection }\end{array}$ \\
\hline 13:28 & $\begin{array}{l}\text { Became restless and unconscious; supine } \\
\text { position and } 6 \mathrm{~L} / \mathrm{min} \text { oxygen inhalation after } \\
\text { systemic air embolism was confirmed }\end{array}$ \\
\hline $13: 57$ & $\begin{array}{l}\text { NO abnormalities on head CT; pulmonary } \\
\text { hemorrhage and pneumothorax on chest CT }\end{array}$ \\
\hline $14: 15$ & Transferred to the Department of Neurology \\
\hline $15: 38$ & Acute cerebral infarction on head MRI \\
\hline Day 2 00:00 & $\begin{array}{l}\text { Shortness of breath, shallow and fast breathing, } \\
\mathrm{SpO}_{2} 60 \%\end{array}$ \\
\hline $00: 15$ & $\begin{array}{l}30 \mathrm{ml} \text { of dark red blood through a sputum suction, } \\
\mathrm{SpO}_{2} 60 \%\end{array}$ \\
\hline $00: 41$ & $\begin{array}{l}\text { Announced the patient dead after non-invasion } \\
\text { rescue }\end{array}$ \\
\hline
\end{tabular}

$\mathrm{SpO}_{2}$, pulse oxygen saturation.

punctured pulmonary vein directly through the puncture needle. (II) The air in the lung enters the pulmonary vein through the puncture channel. When the puncture needle passes through the cavity, bronchus, or normal alveolar tissue and simultaneously punctures the adjacent pulmonary vein, an airway-pulmonary vein fistula could be formed. If the intrapulmonary pressure is higher than the pulmonary venous pressure caused by the patient's Valsalva movement or cough, air could enter the pulmonary vein through the needle path. (III) The air enters the pulmonary artery for various reasons and then enters the pulmonary vein through pulmonary microcirculation or pulmonary arteriovenous fistula $(9,10)$.

In this case, we could see a small branch of the pulmonary vein on the puncture path and the inflated bronchus inside the lesion (Figure 6). When the puncture needle was withdrawn, the patient had a severe cough, which probably caused air to enter the pulmonary vein through the airway-pulmonary vein fistula. Fatal air embolism includes coronary artery embolism and cerebral artery embolism. Experiments have shown that $2 \mathrm{~mL}$ of air in the cerebral artery and $0.5-1 \mathrm{~mL}$ of air in the coronary artery could result in fatal consequences $(2,11)$. Spinal artery air embolism is also a rare complication; so far, only one case has been reported (12). It mainly manifests as nerve damage

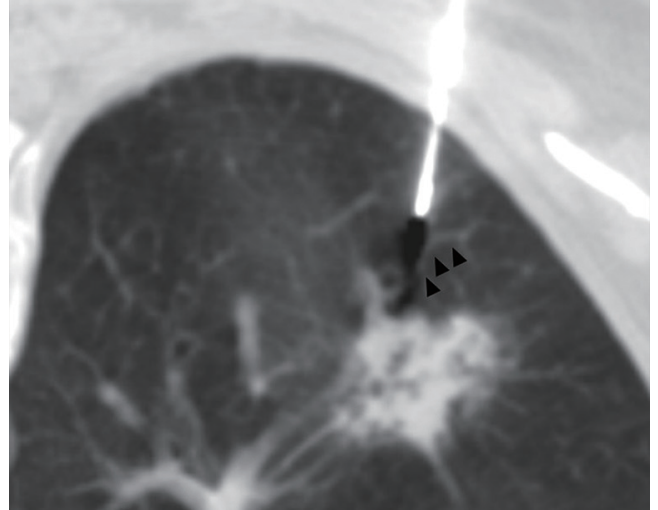

Figure 6 CT showed a small branch of the pulmonary vein on the puncture path (arrowheads) and the inflated bronchus inside the lesion. CT, computed tomography.

symptoms due to spinal cord ischemic infarction, including paraplegia and motor and sensory disturbances (13). In this case, the spinal artery air embolism occurred in the left spinal artery at the eighth thoracic vertebra level, which may be related to the loss of muscle strength in the lower limbs.

During the lung biopsy process, if patients have cerebral vascular embolism symptoms such as hemianopia, limb weakness, hemiplegia, lethargy, dysphasia, loss of consciousness, or coronary artery embolism symptoms (such as arrhythmia, BP drop, acute coronary syndrome, cardiac arrest, shock, etc.), the possibility of air embolism should be considered. A chest CT scan should be performed immediately to determine whether there is air in the systemic circulation. Patients diagnosed with air embolism should be placed in the supine position, right supine position, or head-down-feet-high position and should be given a high concentration oxygen and life support treatment (14). It has been shown that hyperbaric oxygen therapy is an effective method for treating systemic air embolism, which should be carried out as soon as possible after the patient's vital signs are stabilized (15).

In this case, several complications occurred, all of which were related to the patient's death. The direct cause of death was asphyxia caused by pulmonary hemorrhage, as the patient showed hemoptysis and pulmonary hemorrhage around the puncture needle. An intramuscular injection of hemostatic treatment (thrombin, 2 units) was administered after the procedure; however, not enough attention was paid. Hemostatic treatment should continue to be administered if persistent bleeding is suspected, which should be alerted 
through effective means, such as auscultation, bedside $\mathrm{X}$-ray, etc. Through a subsequent investigation, we learned that the family members had helped the patient turn over before the patient had sudden dyspnea, which may have caused blood to flow into the trachea and cause asphyxiation. Patients with pulmonary hemorrhage should be placed in a diseased lateral recumbent position to prevent blood from flowing into the airway and the healthy side of the lung. In this case, the patient could not actively excrete blood from the trachea and lungs due to vague consciousness; regular sputum suction is helpful for patients to expel blood from the airway. In this case, air embolism was a rare and dangerous complication that caused obvious symptoms of cerebral embolism, which obscured the symptoms of pulmonary hemorrhage and made us underestimate the risk of pulmonary hemorrhage. This case reminds us that attention should also be paid to other complications when some serious complications are encountered.

\section{Acknowledgments}

Funding: None.

\section{Footnote}

Conflicts of Interest: All authors have completed the ICMJE uniform disclosure form (available at http://dx.doi. org/10.21037/qims-20-1290). The authors have no conflicts of interest to declare.

Ethical Statement: The authors are accountable for all aspects of the work in ensuring that questions related to the accuracy or integrity of any part of the work are appropriately investigated and resolved. All procedures performed in studies involving human participants were in accordance with the ethical standards of the institutional and/or national research committee(s) and with the Helsinki Declaration (as revised in 2013). Written informed consent was obtained from the patient's son for publication of this article and any accompanying images.

Open Access Statement: This is an Open Access article distributed in accordance with the Creative Commons Attribution-NonCommercial-NoDerivs 4.0 International License (CC BY-NC-ND 4.0), which permits the noncommercial replication and distribution of the article with the strict proviso that no changes or edits are made and the original work is properly cited (including links to both the formal publication through the relevant DOI and the license). See: https://creativecommons.org/licenses/by-nc-nd/4.0/.

\section{References}

1. Wu CC, Maher MM, Shepard JA. Complications of CT-guided percutaneous needle biopsy of the chest: prevention and management. AJR Am J Roentgenol 2011;196:W678-82.

2. Richardson CM, Pointon KS, Manhire AR, Macfarlane JT. Percutaneous lung biopsies: a survey of UK practice based on 5444 biopsies. Br J Radiol 2002;75:731-5.

3. Tomiyama N, Yasuhara Y, Nakajima Y, Adachi S, Arai Y, Kusumoto M, Eguchi K, Kuriyama K, Sakai F, Noguchi M, Murata K, Murayama S, Mochizuki T, Mori K, Yamada K. CT-guided needle biopsy of lung lesions: a survey of severe complication based on 9783 biopsies in Japan. Eur J Radiol 2006;59:60-4.

4. Ibukuro K, Tanaka R, Takeguchi T, Fukuda H, Abe S, Tobe K. Air embolism and needle track implantation complicating CT-guided percutaneous thoracic biopsy: single-institution experience. AJR Am J Roentgenol 2009;193:W430-6.

5. Hiraki T, Fujiwara H, Sakurai J, Iguchi T, Gobara H, Tajiri N, Mimura H, Kanazawa S. Nonfatal systemic air embolism complicating percutaneous CT-guided transthoracic needle biopsy: four cases from a single institution. Chest 2007;132:684-90.

6. Ishii H, Hiraki T, Gobara H, Fujiwara H, Mimura H, Yasui K, Doke T, Mukai T, Kurokawa H, Ando Y, Hase S, Iguchi T, Yabuki T, Omae K, Tajiri N, Mitsuhashi T, Kanazawa S. Risk factors for systemic air embolism as a complication of percutaneous CT-guided lung biopsy: multicenter case-control study. Cardiovasc Intervent Radiol 2014;37:1312-20.

7. Freund MC, Petersen J, Goder KC, Bunse T, Wiedermann F, Glodny B. Systemic air embolism during percutaneous core needle biopsy of the lung: frequency and risk factors. BMC Pulm Med 2012;12:2.

8. Yoshida R, Yoshizako T, Nakamura M, Ando S, Maruyama M, Maruyama M, Takinami Y, Tamaki Y, Nakamura T, Kitagaki H. Nonfatal air embolism complicating percutaneous CT-guided lung biopsy and VATS marking: Four cases from a single institution. Clin Imaging 2018;48:127-30.

9. Cheng HM, Chiang KH, Chang PY, Chou YF, Huang HW, Chou AS, Yen PS. Coronary artery air embolism: a potentially fatal complication of CT-guided percutaneous 
lung biopsy. Br J Radiol 2010;83:e83-5.

10. Monnin-Bares V, Chassagnon G, Vernhet-Kovacsik H, Zarqane H, Vanoverschelde J, Picot MC, Bommart S. Systemic air embolism depicted on systematic whole thoracic $\mathrm{CT}$ acquisition after percutaneous lung biopsy: Incidence and risk factors. Eur J Radiol 2019;117:26-32.

11. Ornelas E, Fernandez-Vilches S, Gallardo X, Mesquida J. Massive coronary air embolism after CT-guided lung needle biopsy. Intensive Care Med 2018;44:1748-9.

12. Sun C, Bian J, Lai S, Li X. Systemic air embolism as a complication of CT-guided percutaneous core needle lung biopsy: A case report and review of the literature. Exp Ther Med 2015;10:1157-60.

Cite this article as: Fang $\mathrm{X}, \mathrm{Li}$ J, Sun B, Liu M, Tang Z. Underestimated pulmonary hemorrhage - a fatal complication combined with systemic air embolism after CT-guided lung biopsy: a case description. Quant Imaging Med Surg 2021;11(11):4661-4666. doi: 10.21037/qims-20-1290
13. Houten JK, Swiggett SJ, Hadid B, Choueka DM, Kinon MD, Buciuc R, Zumofen DW. Neurologic Complications of Preoperative Embolization of Spinal Metastasis: A Systemic Review of the Literature Identifying Distinct Mechanisms of Injury. World Neurosurg 2020;143:374-88.

14. Balsara ZN, Burks DD. Hyperbaric oxygen therapy for arterial air embolism. AJR Am J Roentgenol 2007;188:W98; author reply W99.

15. Hare SS, Gupta A, Goncalves AT, Souza CA, Matzinger F, Seely JM. Systemic arterial air embolism after percutaneous lung biopsy. Clin Radiol 2011;66:589-96. 